\title{
COMPETENCIAS DIGITALES Y FORMACIÓN INICIAL DEL PROFESORADO EN EDUCACIÓN SUPERIOR A DISTANCIA
}

\author{
Marcos Andrei Ota \\ marcos.ota@cruzeirodosul.edu.br \\ https://orcid.org/0000-0003-1411-3439 \\ São Paulo, Brasil. \\ Universidade Cidade de São Paulo (UNICID, Brasil) \\ Sara Dias-Trindade \\ sara.trindade@uc.pt \\ http://orcid.org/0000-0002-5927-3957 \\ Universidade de Coimbra, CEIS20, Faculdade de Letras \\ Coimbra, Portugal. \\ Andrea Borelli \\ andrea.borelli@cruzeirodosul.edu.br \\ https://orcid.org/0000-0003-3621-4070 \\ Universidade Cruzeiro do Sul (UNICSUL) \\ São Paulo, Brasil.
}

Recibido: 13/12/2020 Aceptado: 01/02/2021

\begin{abstract}
Resumen
Este estudio propone importantes reflexiones sobre la formación de estudiantes de pregrado que han optado por cursos superiores a distancia. También se buscó discutir la relevancia de la competencia digital temática como conocimiento necesario para enseñar y aprender en una sociedad hiperconectada. Se trata de un estudio exploratorio, con análisis descriptivo apoyado en referencias bibliográficas, basado en el uso del cuestionario Competencia Digital del estudiante universitario (CODIEU) en una versión traducida y adaptada de los estudios de Casillas-Martín et al (2018) cuya finalidad fue perfilar a estos estudiantes, analizando el nivel de sus competencias digitales desde cuatro dimensiones: conocimiento sobre tecnologías digitales, gestión de dispositivos, herramientas y servicios y actitud hacia las TIC. Un total de 853 representaron la muestra. A partir de los resultados obtenidos, los participantes demostraron tener un buen conocimiento y uso de plataformas, dispositivos y herramientas digitales, pero con indicadores más conservadores. Está claro que si bien existe una comprensión de la relevancia de las competencias digitales para la docencia, las instituciones se quedan con la misión de repensar sus prácticas y currículum, de modo que estos futuros profesionales de la educación sean competentes digitalmente para enseñar en diferentes espacios de aprendizaje.
\end{abstract}

Palabras clave: Competencias Digitales. Enseñanza superior. Educación a distancia. Formación de profesores. 


\title{
COMPETÊNCIAS DIGITAIS E A FORMAÇÃO INICIAL DE PROFESSORES NO ENSINO SUPERIOR A DISTÂNCIA
}

\begin{abstract}
Resumo
Este estudo propõe reflexões importantes quanto a formação dos estudantes de licenciatura que optaram por cursos superiores a distância. Buscou-se ainda, discutir a relevância da temática competência digital como um saber necessário para ensinar e aprender numa sociedade hiperconectada. Trata-se de um estudo exploratório, com análise descritiva suportada por referenciais bibliográficos, tomando como base a utilização do questionário Competência Digital do Estudante Universitário (CODIEU) numa versão traduzida e adaptada dos estudos de Casillas-Martín et al (2018) cujo intuito foi traçar um perfil desses estudantes, analisando o nível das suas competências digitais a partir de quatro dimensões: conhecimento sobre tecnologias digitais, gerenciamento de dispositivos, ferramentas e serviços e atitude perante as Tecnologias da Informação e Comunicação (TICs). Um total de 853 representou a amostra. Dos resultados obtidos, os participantes mostraram ter um bom conhecimento e uso das plataformas, devices e ferramentas digitais, todavia com indicadores mais conservadores. Percebe-se que, embora haja um entendimento sobre a relevância das competências digitais para atuação docente, as instituições ficam com missão de repensar suas práticas e currículo, para que esses futuros profissionais da educação sejam proficientes digitalmente para ensinar em diferentes espaços de aprendizagem.
\end{abstract}

Palavras-chave: Competências Digitais. Ensino Superior. Educação a Distância. Formação de Professores.

\section{DIGITAL COMPETENCIES AND INITIAL TEACHER TRAINING PROGRAMS IN DISTANCE HIGHER EDUCATION}

\begin{abstract}
This study proposes important reflections regarding the training of undergraduate students who have opted for higher distance courses. It was also sought to discuss the relevance of the thematic digital competence as a necessary knowledge to teach and learn in a hyperconnected society. It is an exploratory study, with descriptive analysis supported by bibliographic references, based on the use of the questionnaire Digital Competence of the university student (CODIEU) in a translated and adapted version of the studies by Casillas-Martín et al (2018) whose purpose was to identify these students'profile, analyzing the level of their digital competences from four dimensions: knowledge about digital technologies, device management, tools and services and attitude towards ICTs. A total of 853 represented the sample. From the results obtained, the participants showed to have a good knowledge and use of platforms, devices and digital tools, however with more conservative indicators. It is clear that although there is an understanding of the relevance of digital competences for teaching, institutions are left with a mission to rethink their practices and curriculum, so that these future education professionals are digitally proficient to teach in different learning spaces.
\end{abstract}

Keywords: Digital Competencies. High Education. Distance Learning. Teacher training. 


\section{Educação e competências digitais}

A escola enfrenta desafios entre o modelo de ensino convencional e o mundo conectado e em rápida evolução. O conhecimento agora é compartilhado sem restrições de domínio, com acesso ilimitado, a qualquer hora, sem horas predeterminadas e em qualquer lugar. Segundo Prensky (2001), os alunos de hoje são de uma geração que cresceu com a tecnologia, por isso são familiares como se fossem feitos do mesmo “material”. Porém, é necessária uma capacitação desses mesmos alunos para um uso educativo das competências digitais. Nesse novo cenário educacional, professores e alunos despontam como autores do conhecimento e podem utilizar qualquer ferramenta digital, para promover interações e dinamizar os processos de aprendizagem.

Diante dessas circunstâncias, as competências digitais exigidas nos processos educacionais continuam sendo um fator importante para os programas de formação inicial de professores, muito mais do que isso, exigem ações no currículo de cursos superiores de licenciatura para acompanhar todas as transformações causadas pela inclusão digital no campo educacional. Em especial no cenário brasileiro, podemos destacar a Resolução CNE/CP No 2 (Brasil, 2019) publicada pelo Ministério da Educação que cria a Base Nacional Comum para Formação Inicial de Professores da Educação Básica e tomou como referência a Base Nacional Comum Curricular (BNCC), que prevê os direitos de aprendizagem de todos os alunos das escolas brasileiras e estabelece as diretrizes e habilidades que irão nortear a formação inicial, apontando quais competências deverão ser desenvolvidas nos futuros professores.

Importa ressaltar que ambos os instrumentos regulatórios, evidenciam a importância de se refletir sobre um nível de proficiência digital adequado com o desafio de preparar os estudantes para a viver numa sociedade hiperconectada. Os trechos 2, 4 e 5 a seguir, corroboram para exemplificar as questões supracitadas no âmbito da formação inicial de professores da educação básica, quando observada pelo aspecto das competências digitais:

(...) 2. Pesquisar, investigar, refletir, realizar a análise crítica, usar a criatividade e buscar soluções tecnológicas para selecionar, organizar e planejar práticas pedagógicas desafiadoras, coerentes e significativas.

(...) 4. Utilizar diferentes linguagens - verbal, corporal, visual, sonora e digital - para se expressar e fazer com que o estudante amplie seu modelo de expressão ao partilhar informações, experiências, ideias e sentimentos em diferentes contextos, produzindo sentidos que levem ao entendimento mútuo. 
5. Compreender, utilizar e criar tecnologias digitais de informação e comunicação de forma crítica, significativa, reflexiva e ética nas diversas práticas docentes, como recurso pedagógico e como ferramenta de formação, para comunicar, acessar e disseminar informações, produzir conhecimentos, resolver problemas e potencializar as aprendizagens (BRASIL, 2019, p.13)

De Camargos Júnior (2020) reforça esta ideia ao mencionar sobre a utilização de Tecnologias Digitais de Informação e Comunicação (TDIC) como uma das possibilidades de mediação de conteúdos na Educação Básica, destacando as contribuições de ordem ética, segura e crítica dessas tecnologias ao desenvolver competências específicas em estudantes de Licenciatura, sem perder de vistas uma abordagem didático-pedagógica.

Ao reunir todas essas contribuições, nota-se a necessidade de um esforço hercúleo por parte das instituições de ensino superior ao conceber modelos e programas de Licenciatura na modalidade a distância, uma vez que o estudante em formação inicial vivenciará toda experiência de aprendizagem e aquisição de novos saberes do fazer docente por meio do usa das tecnologias digitais, especificamente, plugado aos ambientes virtuais de aprendizagem. Tal preocupação emerge pelo fato de garantir que todas as competências sejam desenvolvidas para o exercício da profissão e ao estímulo da cultura de uma educação continuada, habilitando os estudantes para uma atuação docente sem barreiras e transitem em diferentes espaços de aprendizagem. Ademais, se considerarmos os últimos dados do Censo Ead.BR, o perfil do estudante universitário brasileiro é caracterizado como alunos que trabalham e estudam, tal fato, nos leva a considerar que o fator tempo e os aspectos de adaptação ao formato do curso são fatores chaves para as instituições repensarem o projeto pedagógico do curso para a jornada acadêmica desses estudantes.

Flores \& Roig (2016) indicam que diferentes estudos remetem a competência digital para uma combinação de elementos relacionados com a alfabetização informacional e ao domínio técnico de ferramentas tecnológicas e digitais, mas também incorporando aspetos cognitivos e comunicativos, bem como éticos e legais (p. 210).

A competência digital diz respeito à competência para utilizar recursos digitais em diferentes áreas e com diferentes objetivos, sendo importante a capacidade de fazer um uso crítico desses mesmos recursos, conseguindo distinguir que recursos são mais eficazes para melhor atingir diferentes objetivos. Dias-Trindade \& Ferreira (2020) referem que, na profissão docente, "Estas competências digitais incluem, precisamente, a capacidade de trabalhar em 
ambientes digitais e de mobilizar conhecimento e atitudes para um uso efetivo em contexto profissional, neste caso, um ambiente educativo" (p. 183).

No que aos estudantes diz respeito, as competências digitais necessárias remetem para "la capacidad para adquirir los conocimientos necesarios para manejarse en la sociedade del conocimiento y ser capaces de utilizar adecuadamente las TDIC para buscar, evaluar, seleccionar, gestionar y comunicar la información en cualquier ámbito de especialización (Casillas Martín et al., 2018, p. 71).

Também Da Silva e Behar (2019) trazem um mapeamento sobre as competências digitais dos alunos da educação a distância brasileiro, ressaltando a importância de compreender os diferentes perfis ligados ao processo de ensinar e aprender em prol do uso mais adequado das tecnologias digitais, pois “aprender exclusivamente através de recursos on-line provoca a construção de novos conhecimentos, novas habilidades e novas atitudes que embasam as necessidades desta aprendizagem mediada pelas tecnologias digitais.”(p. 22). De forma objetiva, as autoras sinalizam que o aluno que se aventura a estudar em cursos a distância fazse necessário conhecimento próprio da tecnologia e de suas possibilidades, sendo fundamental observar quais competências são necessárias para os diferentes perfís de alunos ao utilizar as tecnologias como recurso para aprendizagem.

Os estudos liderados por Araripe e Lins (2019) apresentaram referenciais de competências digitais que nos permitem sistematizar algumas discussões que fizemos até aqui, no que se referem aos componentes curriculares de cursos de formação inicial na habilitação de profissionais que possam reunir conhecimentos, atitudes e habilidades digitais composto pela pluralidade de saberes teóricos e práticos referentes às áreas pedagógica, cidadania digital e desenvolvimento profissional.

É importante conhecer a competência digital dos alunos e entender esta questão como um processo em constante crescimento e que deve ser estimulada durante o período de formação. É necessário mapear a realidade concreta para observar que parcela dos alunos mais se aproxima da literacia digital (um estádio inicial onde se compreende que a tecnologia digital pode contribuir para a estruturação de ambientes de aprendizagem de qualidade e se sabe colocar essas ideias em prática) ou da fluência digital (a capacidade não só de saber fazer o quê com a tecnologia digital para atingir determinado objetivo, mas também saber como o fazer da melhor forma possível) (Dias-Trindade \& Ferreira, 2020). 
Este mapeamento é fundamental para auxiliar na criação de mecanismos que possam colaborar para o desenvolvimento das competências que desejados no futuro professor. Tal competência pode ser experenciada pelo aluno através do gerenciamento de um serviço ou dispositivo que são apresentados a ele durante seu processo de formação na educação a distância.

A expansão do COVID-19 no cenário internacional teve impactos diretos na prática pedagógica de professores da educação básica e evidenciou os desafios da aprendizagem em ambientes digitais. Este cenário tornou mais aguda a necessidade da aquisição de competências digitais e a criação de programas de formação inicial docente que possam caminhar nesta direção e contribuir para preparar devidamente o estudante para o exercício da sua profissão, hoje mais que nunca imersa num mundo cada vez mais digital.

Os dados apresentados pelos Mapa do Ensino Superior (Brasil, 2020) mostram que este estudante tem um perfil claro: trata-se de uma mulher de 19 a 24 anos que mora com os pais, fez o ensino médio em escola pública e precisa trabalhar para obter uma renda de até dois salários mínimos.

Apesar deste dado, deve-se destacar que, entre os jovens que estão em idade de cursar o ensino superior, $61,9 \%$ dos jovens de 18 a 24 anos da classe A (renda de mais de oito saláriosmínimos) estão matriculados no ensino superior, enquanto apenas $10,5 \%$ dos jovens da classe E (renda de meio salário-mínimo) chegam à universidade.

Isso reforça o caráter desigual do acesso ao ensino superior no Brasil, mesmo com a ampliação de matrículas em cursos EAD. A análise realizada pelo Mapa do Ensino Superior indica que o crescimento do setor aconteceu em virtude o esvaziamento dos cursos noturnos e, pode-se imaginar que pela flexibilização dos horários.

No caso dos cursos de formação de professores, público-alvo deste estudo, 53\% dos alunos estão matriculados em cursos a distância, o que deveria garantir intimidade com as tecnologias digitais, o gerenciamento de dispositivos, ferramentas e serviços. Porém, será que esta hipótese é verdadeira?

Neste trabalho analisaremos os resultados de um estudo realizado a partir da tradução e adaptação do questionário Competência Digital dos Estudantes Universitários (CODIEU), validado por Casillas Martín e colegas (2018), com o objetivo de traçar o perfil dos estudantes de diferentes cursos de licenciatura em EaD de uma universidade privada brasileira, ao nível 
das suas competências digitais em quatro dimensões: conhecimento sobre tecnologias digitais, gerenciamento de dispositivos, ferramentas e serviços e atitude perante as TICs.

\section{Metodologia}

\subsection{Amostra}

Este estudo foi realizado online nos meses de setembro a novembro de 2020, numa universidade privada brasileira, tendo sido recolhida uma amostra de 853 estudantes que frequentam cursos de licenciatura em $\mathrm{EaD}$.

Os participantes da amostra estão enquadrados nas seguintes faixas etárias $0,70 \%$ (6) entre 18 e 19 anos, 22,83\% (195) com idade entre 20 e 29 anos, 37,12\% (317) entre 30 e 39 anos, correspondendo a maior fatia dos participantes, seguidos, por 26\% (222) com idades entre 40 e 49 anos, 9,95\% (85) entre 50 e 59 anos, e por fim, maiores de 60 anos 2,58\% (22).

Há predominância do público feminino, com 73,7\% (629) e 26,3\% (224) representando o público masculino. 50,2\% (428) são pessoas casadas, seguidas por 34,8\% (297) são solteiras, seguidas por pessoas em regime de união estável 7,6\% (65), 7\% (60) divorciadas, e por fim, $0,4 \%$ (3) são de viúvos.

Estão distribuídas em todas as regiões do país, com dominância da região sudeste com $68,6 \%$ (585), nas seguintes regiões é possível identificar valores bem similares, por exemplo, sul com 10,8\% (92), centro-oeste com 8,1\% (69), região Nordeste com 7,9\% (67) e, por último, a região norte $4,7 \%(40)$.

$60,1 \%$ (513) residem em moradia própria, seguidos de 25,4\% (217) em casas locadas e o restante, 14,4\% (123) em imóveis cedidos. Esses imóveis estão em sua grande maioria 90,7\% (773) em zona urbana, seguidos por 9,1\% (78) em zona rural e 0,2 (2) em comunidade indígena.

\section{2. $O$ instrumento}

O instrumento usado neste estudo foi o questionário "Competencia Digital Enseñanzas Universitarias (CODIEU)", de Casillas Martín e colegas (2018), traduzido para português do Brasil. 
Este questionário conta com quatro dimensões, dedicadas ao conhecimento em tecnologias digitais (Dimensão 1), gerenciamento de dispositivos (Dimensão 2), ferramentas e serviços (Dimensão 3) e atitude dos estudantes universitários perante as TDICs (Dimensão 4), numa perspectiva holística sobre que dispositivos digitais existem e que tipo de utilização deles pode ser feita, terminando, na quarta dimensão, com uma perspectiva sobre o uso que o estudante entende poder vir a fazer das TICs no seu próprio percurso profissional, dimensão esta que nos parece extremamente relevante quando fazemos a análise das competências digitais de estudantes que serão futuramente docentes.

\section{Resultados e discussão}

\section{Dimensão 1 - Conhecimento em Tecnologias Digitais}

De acordo com os dados obtidos, foi possível afirmar que os participantes detêm um razoável nível de conhecimento sobre as siglas e recursos abordado nessa dimensão, apresentando uma média de 5,6 pontos em 10.

Quando questionados se sabem o que são TICs, 86\% (734) se encaixam no intervalo de "conheço" a "conheço totalmente" o termo, enquanto, 14\% (119) ficaram entre "desconheço totalmente e "desconheço parcialmente". Como podemos constatar referente ao termo TAC, 78,5\% (670) relatam que estão entre o "conhecer" e "conhecer totalmente" o termo, contra, 21,5\% (183) entre "desconheço totalmente e "desconheço parcialmente".

Como exemplo de conhecimento de recursos digitais, podemos dizer que a grande maioria dos entrevistados conhecem o que é a Wikipedia, uma vez que, 93,8\% (800) dizem "conhecer" ou "conhecer totalmente" o recurso, contra apenas, 6,2\% (53) relatam "desconhecer totalmente" ou "desconhecer parcialmente" o recurso mencionado. Outros recursos que podemos usar como exemplo são o Podcast e Vlog, onde 42,6\% (363) e 36\% (307), respectivamente dizem "conhecer totalmente" os recursos e 7,3\% (62) e 14,7\% (125) respectivamente alegam "desconhecer totalmente" tais recursos.

Mesmo conhecendo a maioria dos termos usados na amostra, alguns termos parecem ser desconhecidos pelos participantes, como o termo Mashup, que 40,1\% (342) "desconhecem totalmente" o termo, contra apenas, 7,7\% (66) afirmam "conhecer totalmente" tal nomenclatura. 
Outro item que também é desconhecido pelos participantes é o recurso MOOC, onde 41\% (350) “desconhecem totalmente" do que se trata e 8,1\% (69) "conhecem totalmente".

Conceitos como Wikipedia, objetos de aprendizagem, realidade virtual, realidade aumentada ou alfabetização digital são reconhecidos por estes estudantes (representando valores médios acima de 7,5 pontos em 10). Porém, preocupante é verificar que entre este grupo termos como blearning, mlearning ou licenças creative commons sejam reconhecidos por menos de metade dos participantes (a média nestes itens é inferior a 3,5 pontos em 10).

Figura 1 - Dimensão 1 - Conhecimento em Tecnologias digitais

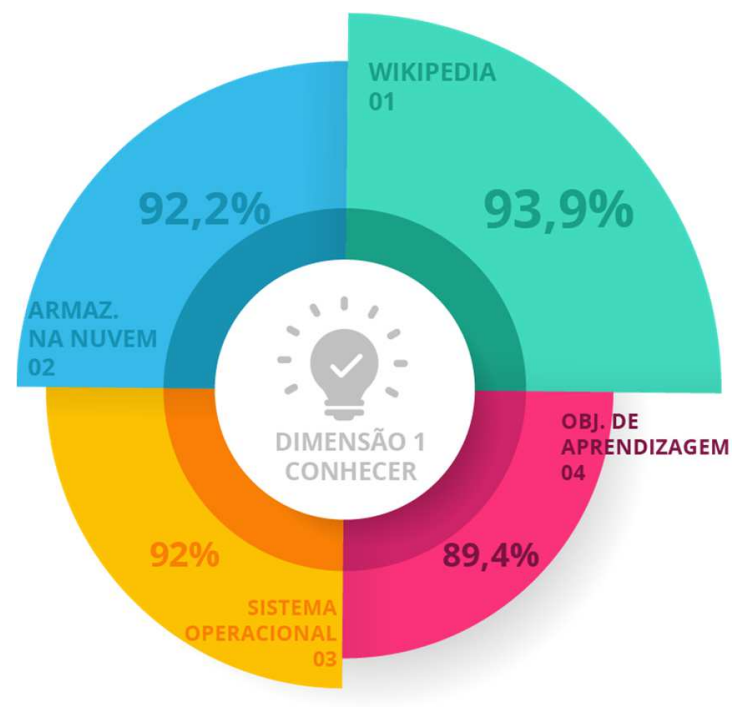

Fonte: dos autores

\section{Dimensão 2 - Gerenciamento de dispositivos}

A partir dos dados coletados, podemos inferir que os participantes da pesquisa possuem um bom nível de competência digital (com uma média de 7,9 pontos em 10). Os participantes foram perguntados sobre seu conhecimento e uso de alguns recursos, entre eles, conhecer e saber utilizar um Tablet, onde 99,3\% (847) se encaixam em "conhecer" e "conhecer totalmente" e 89,93\% (768) estão entre "concorda" e "concordam totalmente" quando questionados sobre saber manusear o recurso. Outro recurso que se destaca em sua utilização é o Smartphone, onde $86,30 \%$ (737) "conhecem totalmente" e 57,26\% (489) sabem utilizar totalmente esse recurso, contra apenas, $0,70 \%$ (6) "desconhecem totalmente" e 1,17\% (10) dizem não saber utilizar o Smartphone. 
Em contraponto, os Wearables foram os recursos que os participantes demonstraram maior desconhecimento, 34,9\% (298) afirmam desconhecer totalmente e 32,6\% (278) afirmam desconhecer totalmente seu uso.

Recursos do nosso cotidiano também foram apontados como ferramentas que os participantes conhecem, entre eles a Lousa interativa, 64,5\% (550) afirmam "conhecer totalmente" e 3,9\% (33) "desconhecem totalmente" o que é esse recurso. E o GPS, onde 84,1\% (717) conhecem totalmente e apenas $0,4 \%$ (3) desconhecem totalmente esse recurso.

Dentre os dispositivos que os participantes afirmam possuir, podemos destacar o Smartphone, onde 92,3\% (787) dos participantes possuem, seguidos pelos dispositivos vestíveis, os Wearables, onde 85,9\% (733) e pelo Notebook, onde 84,5\% (721).

Figura 2 - Gerenciamento de dispositivos

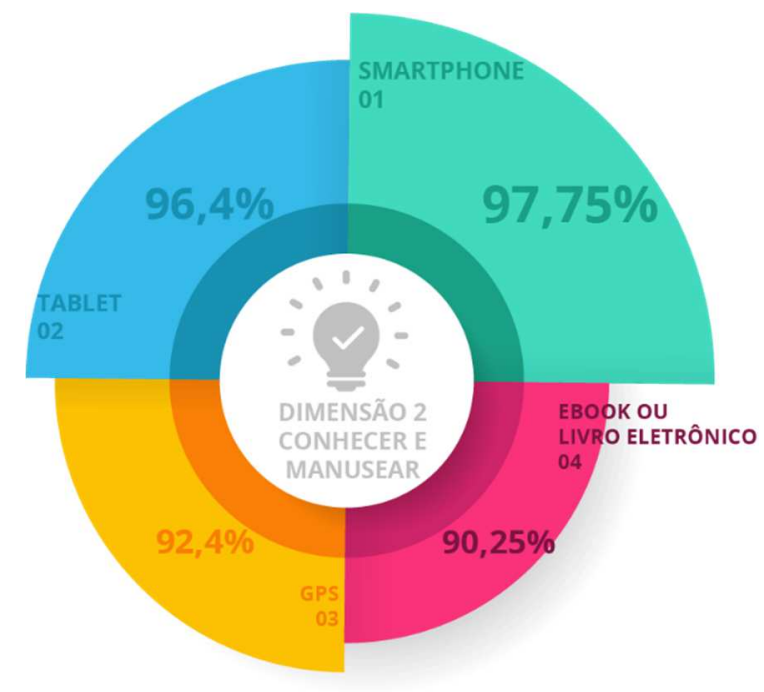

Fonte: dos autores

\section{Dimensão 3 - Ferramentas e serviços}

As informações obtidas nesta dimensão, indicam que os participantes da amostra têm um nível razoável de conhecimento ao manusear ferramentas e serviços ofertados pelas TICs, apresentando uma média de resposta de 6,2 pontos em 10 .

$\mathrm{Na}$ utilização de ferramentas para processamento de texto, apresentações, banco de dados, planilhas, $87,6 \%$ (746) dos dados obtidos indicam que os participantes estão entre o "concordo" e "concordo totalmente" quando questionados sobre o manuseio desses recursos. 
Assim como, na utilização de ferramentas de edição de mídias digitais e ferramentas de busca e documentação, com os seguintes dados obtidos, 79,3\% (676) e 89,9\% (768), respectivamente, estão entre "concorda" e "concorda totalmente" quanto a saber utilizar esses recursos.

É possível notar um certo domínio nas redes sociais, onde 95,4\% (814) indicam estar entre "concordo" e "concordo totalmente", quando questionados quanto ao saber manusear redes sociais. Com destaque para as redes sociais Facebook e Instragram, com índices de 50,3\% (429) e 48,3\% (412), respectivamente, de participantes que afirmam "concordar totalmente" quando questionados sobre saber utilizar essas duas redes sociais.

O domínio das redes sociais por esse público, fica evidente quando questionados sobre a utilização outros serviços, como por exemplo, quando perguntados se possuem um Blog, Site, se consulta ou pública em Wikis, os dados obtidos foram, respectivamente, 79,8\% (681), 79,4\% (677), 59\% (503) e $81,6 \%$ (696).

A utilização de serviços de comunicação é bem utilizada pelos participantes, conforme dados, 45,8\% (391) dizem "concordar totalmente" e 7,7\% (66) "discordar totalmente", quando questionados sobre o seu uso desses serviços.

As respostas mostram que estes estudantes não estão habituados a criar os seus próprios conteúdos digitais. A taxa de resposta, próxima de zero, indica que quase nenhum usa o Linkedin, tem o seu próprio blog ou site, consulta ou publica conteúdos em Wikis.

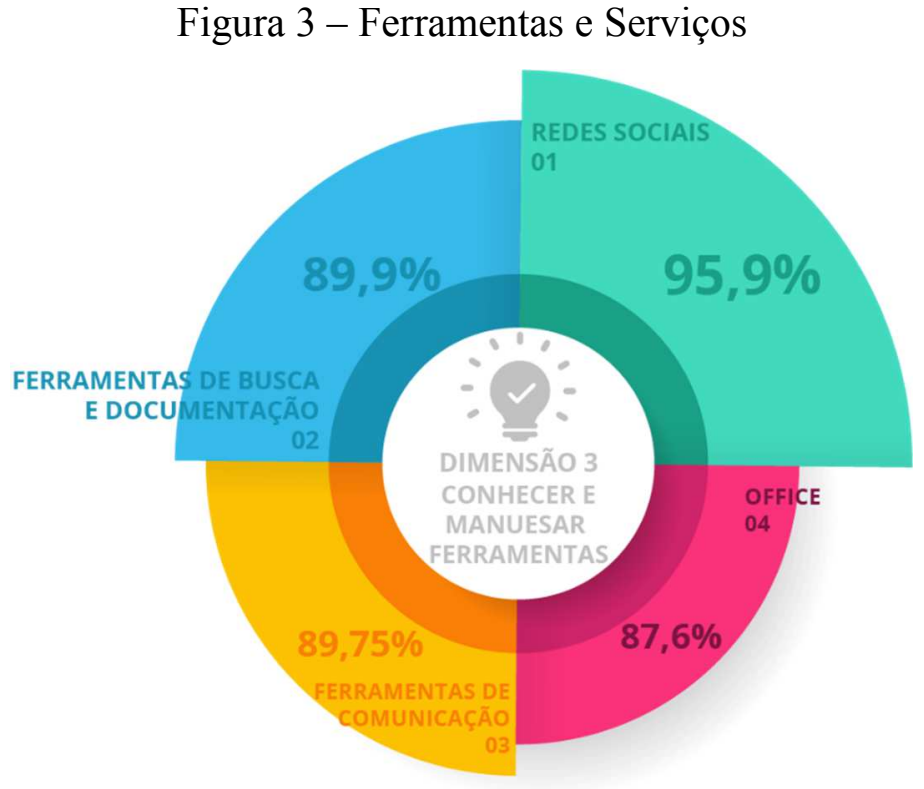

Fonte: dos autores 


\section{Dimensão 4 - Atitude perante as TDIC}

Os participantes da amostra demonstram concordar que as TDICs são necessárias e importantes para o futuro profissional da educação, uma vez que, quando questionados sobre “As TDIC são necessárias e úteis para meu futuro trabalho profissional como educador”, $41 \%$ (350) concordam totalmente com o questionamento, como também, quando questionados sobre a utilidade das TDICs no processo de atualização profissional, 44\% (375).

Também é identificado que os participantes afirmam que as TDICs precisam se "tornar ferramentas habituais no desenvolvimento profissional do educador", 44,2\% (377) e que o Educador deve possuir competência digital para utilizar as TDICs, em sua profissão, 45,4\% (387).

Porém, torna-se preocupante, sobretudo tendo em conta que estes estudantes estão inseridos em cursos de Educação a Distância, verificar que vários entendem as TDIC como um meio de educação frio e distante, preferindo o contato presencial e que cerca de $10 \%$ dos respondentes não veem nas TDIC relevância para o seu futuro profissional na docência.

Figura 4 - Dimensão 4 - Atitude perante as TDICs

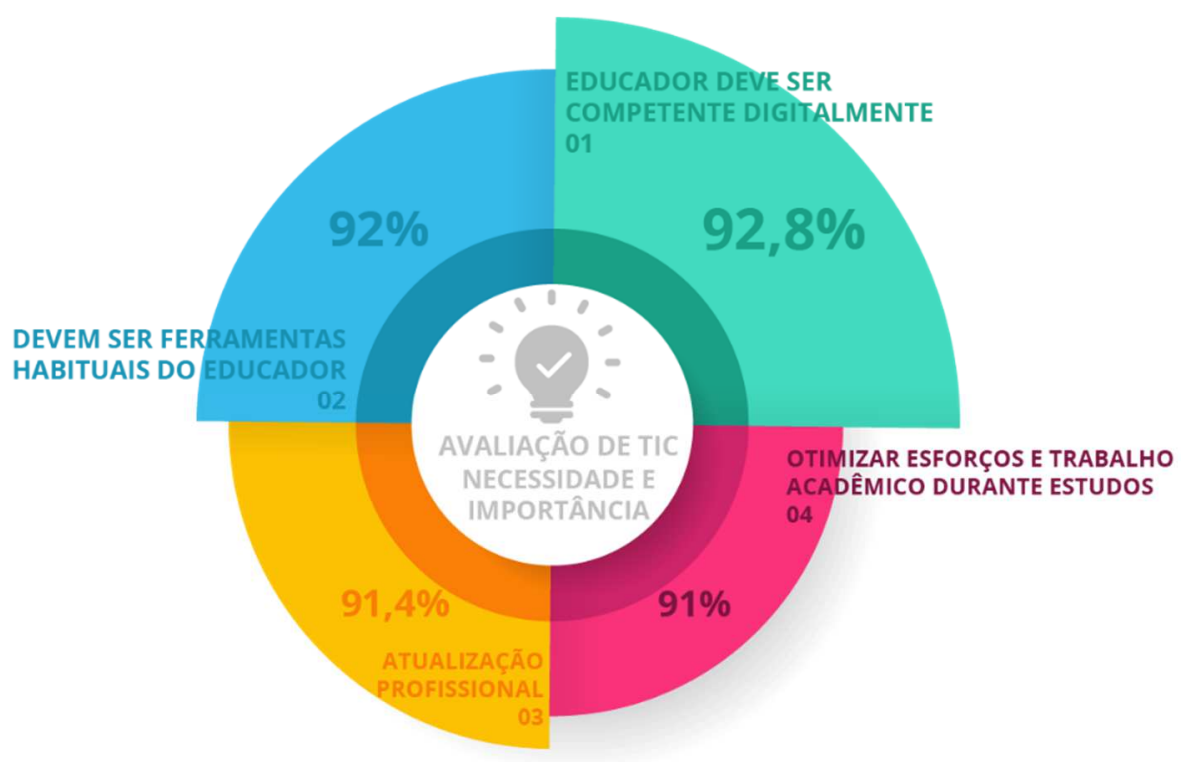

Fonte: dos autores 


\section{Notas finais}

O século em que nos encontramos tem beneficiado cada vez mais do desenvolvimento tecnológico e digital, por vezes considerado avassalador, mas que vem também promovendo uma reconfiguração dos espaços educativos e o repensar de estratégias por forma a adequar a educação às necessidades também elas decorrentes destes mesmos desenvolvimentos.

Muito se vem discutindo sobre competências digitais docentes, mas também a preparação dos estudantes para uma educação cada vez mais digital é bastante necessária, sobretudo quando se trata de estudantes que se encontram em formação para virem eles próprios a ser professores. Chai, Tan, Deng e Koh (2017) referem que "os alunos de hoje podem obter facilmente informações e tutoriais de elevada qualidade, assistir a palestras de especialistas, participar em grupos que lhes interessem particularmente e mesmo publicar seus trabalhos digitais, desde que saibam como aproveitar os ambientes digitais de forma produtiva" (p. 129).

Nesse sentido, o trabalho que aqui se apresenta procurou aferir o nível de competência digital de estudantes de licenciatura, buscando analisar quer o seu nível de competência digital enquanto estudantes, a partir da análise das dimensões 1 a 3 do questionário Competência Digital dos Estudantes Universitários (CODIEU), validado por Casillas Martín e colegas (2018), que nos permitem, a partir das 853 respostas obtidas, traçar um perfil destes estudantes ao nível do conhecimento sobre tecnologias digitais, gerenciamento de dispositivos, ferramentas e serviços.

A Dimensão 4 permitiu-nos aferir a relação que estes estudantes fazem entre tecnologias digitais e educação, preocupando-nos em particular esta análise por se considerar relevante compreender o posicionamento destes futuros professores face à relevância das TIC nos processos educativos, não esquecendo que se trata de estudantes inscritos em cursos de EaD.

Da análise dos resultados obtidos, entende-se que os participantes mostraram ter um bom conhecimento das plataformas e das ferramentas digitais mais conhecidas, e fazem delas uso na sua prática, apesar de o fazerem de uma forma relativamente conservadora. Porém, a partir da análise da Dimensão 4 percebe-se que os estudantes entendem a mais valia de um conhecimento das diferentes vertentes da competência digital na profissão docente, apesar de considerarem os ambientes digitais espaços "frios" e preferirem os espaços presenciais de ensino e aprendizagem. 
Uma vez que "o repensar dos espaços de aprendizagem (on-line, presencial) conectado ao uso pedagógico das tecnologias digitais possibilitará elevar os indicadores institucionais para as competências essenciais que se deseja desenvolver nos estudantes" (Ota \& Dias-Trindade, 2020, p. 223). A pertinência desta questão leva-nos a considerar que estes resultados nos indicam a necessidade de uma aposta em mais formação ao nível das competências digitais, formação esta que deverá ser adequada não só à sua capacitação enquanto estudantes, mas tendo em vista já uma preparação para a sua atividade profissional docente, por forma a que estes futuros profissionais progridam nas suas competências digitais, em particular nas que se relacionam com a atividade docente, e evoluam no sentido da fluência digital.

\section{Referências}

Araripe, J. P. G. A.; LINS, Walquíria C. B. (2020). Competências Digitais na Formação Inicial de Professores. São Paulo: CIEB; Recife: CESAR School. E-book em pdf.

Brasil. (2019). Resolução CNE/CP n. 2, de 20 de dezembro de 2019. Disponível em: http://portal.mec.gov.br/docman/dezembro-2019-pdf/135951-rcp002-19/file

Brasil, (2020). Mapa do Ensino Superior. SEMESP. SEMESP, São Paulo, 10

Casillas Martín, S. et al. (2018). Estudio psicométrico de un cuestionario para medir la competencia digital de estudiantes universitarios (CODIEU). EKS, 19(3), 69-81. DOI: https://doi.org/10.14201/eks20181936981

Chai, C. S., Tan, L., Deng, F. \& Koh, J.H.L. (2017). Examining pre-service teachers' design capacities for webbased 21 st century new culture of learning. Australasian Journal Education Technology, 33(2), 129-142. doi: https://doi.org/10.14742/ajet.3013

Da Silva, K. K. A.; Behar, P. A. (2019). Alunos da Ead on-line do Brasil e competências digitais. Revista EDaPECI, v. 19, n. 2, p. 21-39.

De Camargos Júnior, A. P. (2020). Abordagem de competências digitais em Cursos de pedagogia de universidades públicas na região de Ubá/MG/Digital skills approach in public universities pedagogy courses in the region of Ubá/MG. Brazilian Journal of Development, v. 6, n. 3, p. 10805-10818, 2020.

Dias-Trindade, S.; Ferreira, A. G. (2020). Digital teaching skills: DigCompEdu CheckIn as an evolution process from literacy to digital fluency. ICONO14. 18(2). 162-187. DOI: 10.7195/ri14.v18i1.1519

Flores, C. \& Roig, R. (2016). Diseño y validación de una escala de autoevaluación de competencias digitales para estudiantes de Pedagogía. Píxel-Bit. Revista de Medios y Educación. 48, janeiro, 209-224. doi: http://dx.doi.org/10.12795/pixelbit.2016.i48.14

Ota, M., \& Dias-Trindade, S. (2020). Ambientes digitais de aprendizagem e competências digitais: conhecer o presente para agir num futuro pós-COVID. Revista Interfaces Científicas - Educação. 10(1). 211-226. DOI: 10.17564/2316-3828.2020v10n1p211-226

Prensky, M. (2001). Digital natives digital immigrants, part 1. On the Horizon, 9 (5), October. 